\title{
Online Appendix for \\ Crossing Party Lines: The Effects of Information on Redistributive Politics
}

\author{
Katherine Casey
}

February 24, 2015

\section{Appendix A. Proof of Proposition 1}

Let $t_{j}=v\left(\omega+t_{a j}\right)-v\left(\omega+t_{b j}\right)$ denote the consumption utility differential for jurisdiction $j$ in Equation (9). The first order conditions for Party $A$ and $B$ respectively are:

$$
\begin{aligned}
& v^{\prime}\left(\omega+t_{a j}\right) f_{j}\left(t_{j}\right)=\lambda \\
& v^{\prime}\left(\omega+t_{b j}\right) f_{j}\left(t_{j}\right)=\mu
\end{aligned}
$$

Constant shadow prices indicate that gains in expected votes with respect to marginal shifts in transfers should be equal across jurisdictions. The ratio of the scalars $(\lambda / \mu)$ holds constant, while exhausting the budget, only if each party promises the same amount to any given jurisdiction $\left(t_{a j}=t_{b j}=Y_{j} \forall j\right)$. Voter consumption is thus identical under either party and implies $t_{j}=0$. By the translate assumption, rewrite each jurisdictional density as a function of the common density, $f_{j}(0)=f\left(0+\alpha_{j}\right)$, for the general first order condition:

$$
v^{\prime}\left(\omega+Y_{j}\right)=\frac{\lambda}{f\left(\alpha_{j}\right)}
$$

The concavity of $v(\cdot)$ and the unimodal and symmetric nature of $f(\cdot)$ imply that transfers $\left(Y_{j}\right)$ are decreasing in the absolute value of the expected bias of jurisdictions $\left(\left|\alpha_{j}\right|\right)$. Assume that $v^{\prime}(0)$ is sufficiently high to generate an interior solution.

To establish uniqueness, the concavity of $v(\cdot)$ implies that for any two solutions $(\lambda, Y)$ and $\left(\lambda^{\prime}, Y^{\prime}\right)$ to (21) that are not equal, $\lambda<\lambda^{\prime}$ implies $Y>Y^{\prime}$ in all jurisdictions, which violates 
the budget constraint. LW further prove that $\left|f^{\prime}(0)\right| / f(0) \leq\left|v^{\prime \prime}(\omega+Y)\right| /\left(v^{\prime}(\omega+Y)\right)^{2}$ is a necessary condition for existence, which is satisfied given the symmetry of $f(\cdot)\left(\right.$ as $\left.f^{\prime}(0)=0\right)$.

\section{Appendix B. Proof of Proposition 2}

Set the consumption differential in the right hand side of Equation (4) to zero. The voter chooses Party $A$ if the perceived quality advantage of candidate $B$ is not large enough to outweigh the voter's party loyalty to $A$ (recalling that $\Delta p_{i}=b_{i}-a_{i}$ ):

$$
\text { Vote } \mathrm{A} \text { if }: \delta \theta_{i j} \leq-\Delta p_{i}
$$

For voters, party preference is a known scalar, while relative candidate quality is based on a random draw from the quality distribution. Considering the same voter over multiple elections, the probability that the voter chooses Party $A$ in any particular election is thus:

$$
\operatorname{Pr}(\text { Vote } A)=\operatorname{Pr}\left[\delta \theta_{i j} \leq-\Delta p_{i}\right]
$$

This probability is the cumulative density function of perceived quality advantage (of candidate $B$ over $A$, from Equation (3)) evaluated at the voter's own party preference (for party $A$ over $B)$. Standardizing this distribution yields:

$$
\operatorname{Pr}(\text { Vote } A)=\Phi\left(\frac{-\Delta p_{i}}{\left(\sigma_{q}^{4} /\left(\sigma_{q}^{2}+\sigma_{v}^{2}\right)\right)^{1 / 2}}\right)
$$

Crossing party lines is a vote for Party $A$ if the voter is Type $B$ (i.e. $\Delta p_{i}>0$ ) and a vote for Party $B$ if the voter is Type $A\left(\Delta p_{i}<0\right)$. Thus for a Type $B$ voter, the probability

of crossing party lines is simply (24). (The argument is symmetric for Type $A$.) Improving signal quality increases the variance of the perceived quality distribution, thereby increasing the denominator of the argument in (24). Since the numerator for a Type $B$ voter is less than zero, this increases the argument overall. As the CDF is increasing in its argument, conclude that improving information increases the probability of crossing party lines.

\section{Appendix C. Proof of Proposition 3}

Consider the case of positive expected jurisdictional bias (the case for negative is symmetric). Recall that Proposition 1 implies spending that is decreasing in partisanship. Applying the Implicit Function Theorem to the first order condition in (10) generates a general expression for this derivative and one specific to the normal distribution case:

$$
\frac{\partial Y_{j}}{\partial \alpha_{j}}=\frac{-\lambda \frac{\partial f\left(\alpha_{j}\right)}{\partial \alpha_{j}}}{v^{\prime \prime}\left(\omega+Y_{j}\right) f\left(\alpha_{j}\right)^{2}}=\frac{\lambda \alpha_{j}(2 \pi)^{1 / 2}}{v^{\prime \prime}\left(\omega+Y_{j}\right) \delta \sigma_{q} \exp \left(\frac{-\alpha_{j}^{2}}{2 \delta^{2} \sigma_{q}^{2}}\right)} \leq 0
$$


The sign of this derivative is nonpositive for the normal distribution and holds quite generally: $f\left(\alpha_{j}\right)$ is decreasing in its argument for any unimodal distribution; $v^{\prime \prime}(\cdot)$ is negative given the concavity assumption; and $f\left(\alpha_{j}\right)$ is positive by definition.

Providing better information $\left(\sigma_{\nu} \rightarrow 0\right)$ increases voter responsiveness $(\delta)$ to candidate quality (as $\frac{\partial \delta}{\partial \sigma_{\nu}}<0$ ), which increases the variance of the parties' estimated distribution of advantage. Taking the derivative of (25) with respect to $\delta$ shows how spending changes with information provision:

$$
\frac{\partial}{\partial \delta}\left(\frac{\partial Y_{j}}{\partial \alpha_{j}}\right)=\frac{-\lambda\left[\frac{\partial^{2} f\left(\alpha_{j}\right)}{\partial \delta \partial \alpha_{j}} f\left(\alpha_{j}\right)-2 \frac{\partial f\left(\alpha_{j}\right)}{\partial \delta} \frac{\partial f\left(\alpha_{j}\right)}{\partial \alpha_{j}}\right]}{v^{\prime \prime}\left(\omega+Y_{j}\right) f\left(\alpha_{j}\right)^{3}}=\frac{-\lambda \alpha_{j}(2 \pi)^{1 / 2}\left(\alpha_{j}^{2}+\delta^{2} \sigma_{q}^{2}\right)}{v^{\prime \prime}\left(\omega+Y_{j}\right) \delta^{4} \sigma_{q}^{3} \exp \left(\frac{-\alpha_{j}^{2}}{2 \delta^{2} \sigma_{q}^{2}}\right)} \geq 0
$$

As the cross derivative is nonnegative for the normal distribution, conclude that information provision attenuates the slope of party spending with respect to jurisdictional bias.

The generality of this result is less clear than that of (25). Without assuming a specific functional form, the sign of the expression in (26) depends on which term within brackets dominates (the signs on the other terms remain as above and are together a positive multiplier of the expression in brackets). This is nonnegative for the assumption of normally distributed partisan loyalties and candidate quality. If we revised the model to instead incorporate the (also) common assumption of uniformly distributed loyalties and perceived quality, $f(\cdot)$ would take the triangular distribution and (26) would again be unambiguously nonnegative.

Appendix D. Derivation of Propositions 1 to 3 under an alternative objective function

A closer match to the original LW framework would be to assume that parties maximize the expected number of votes they receive within each constituency, as opposed to number of seats won in Parliament. This reformulation does not affect the set up of the voter's decision (Equations 1 through 4) nor the assumptions regarding what parties know about the distributions of party loyalty, candidate quality and the noisy quality signals.

Recall that from the parties' perspective the left hand side of the Vote $A$ expression in Equation (4) is the sum of two normally distributed random variables:

$$
\Delta p_{i}+\delta \theta_{i j} \sim F_{j}(\cdot)=N_{j}\left(\alpha_{j}, \sigma_{\alpha}^{2}\right) \text { where } \sigma_{\alpha}^{2}=\sigma_{p}^{2}+\left(\frac{\sigma_{q}^{2}}{\sigma_{q}^{2}+\sigma_{v}^{2}}\right) \sigma_{q}^{2}
$$

The assumed objective of political parties is now to maximize the total number of votes they receive in each jurisdiction, subject to the budget constraint. ${ }^{1}$ Party $A$ does so by

\footnotetext{
${ }^{1} \mathrm{LW}$ show that the first order condition for the alternative objective of maximizing the probability of winning collapses to that of the plurality case if both parties are equally popular.
} 
choosing a vector of transfers that maximizes the sum of expected votes for $A$. Notice that the probability a voter chooses $A$ is the probability that the random variable in (27) is less than the promised consumption utility differential. Party $A$ thus maximizes this probability with respect to the budget constraint:

$$
\max _{t_{a j}} \sum_{i \in \mathcal{I}_{j}} F_{j}\left[v\left(\omega+t_{a j}\right)-v\left(\omega+t_{b j}\right)\right]-\lambda\left[\sum_{j} n_{j} t_{a j}-n \tau\right]
$$

Party $B$ solves a symmetric problem with respect to $t_{b j}$, with corresponding Lagrange multipliers denoted by $\mu$. The first order conditions for Party $A$ and $B$ respectively are the same as in Equations (19) and (20), where the rationale above again applies and produces the general first order condition of Proposition 1:

$$
v^{\prime}\left(\omega+Y_{j}\right)=\frac{\lambda}{f\left(\alpha_{j}\right)}
$$

where transfers are decreasing in the absolute value of expected party loyalty $\left(\left|\alpha_{j}\right|\right)$.

The derivation of Proposition 2 is unaffected.

To prove Proposition 3 again consider the case where the expected advantage is positive (the case for negative is symmetric). Apply the Implicit Function Theorem to (29) to generate a general expression for the derivative and one specific to the normal distribution:

$$
\frac{\partial Y_{j}}{\partial \alpha_{j}}=\frac{-\lambda \frac{\partial f\left(\alpha_{j}\right)}{\partial \alpha_{j}}}{v^{\prime \prime}\left(\omega+Y_{j}\right) f\left(\alpha_{j}\right)^{2}}=\frac{\lambda \alpha_{j}(2 \pi)^{1 / 2}}{v^{\prime \prime}\left(\omega+Y_{j}\right) \sigma_{\alpha} \exp \left(\frac{-\alpha_{j}^{2}}{2 \sigma_{\alpha}^{2}}\right)} \leq 0
$$

Recall that providing better information to voters increases the variance of the parties' estimated distribution of advantage. Taking the derivative of expression (30) with respect to the variance shows how spending changes when voters have access to better information about candidate quality:

$$
\frac{\partial}{\partial \sigma_{\alpha}^{2}}\left(\frac{\partial Y_{j}}{\partial \alpha_{j}}\right)=\frac{-\lambda\left[\frac{\partial^{2} f\left(\alpha_{j}\right)}{\partial \sigma_{\alpha}^{2} \partial \alpha_{j}} f\left(\alpha_{j}\right)-2 \frac{\partial f\left(\alpha_{j}\right)}{\partial \sigma_{\alpha}^{2}} \frac{\partial f\left(\alpha_{j}\right)}{\partial \alpha_{j}}\right]}{v^{\prime \prime}\left(\omega+Y_{j}\right) f\left(\alpha_{j}\right)^{3}}=\frac{-\lambda \alpha_{j}(2 \pi)^{1 / 2}\left(\alpha_{j}^{2}+\sigma_{\alpha}^{2}\right)}{v^{\prime \prime}\left(\omega+Y_{j}\right) 2 \sigma_{\alpha}^{5} \exp \left(\frac{-\alpha_{j}^{2}}{2 \sigma_{\alpha}^{2}}\right)} \geq 0
$$

For the normal distribution case the sign is nonnegative, indicating that supplying better information to voters attenuates the slope of party spending with respect to the underlying bias of jurisdictions. 
Appendix Figure 1: Map of Raw Expected Partisan Bias at the Constituency Level

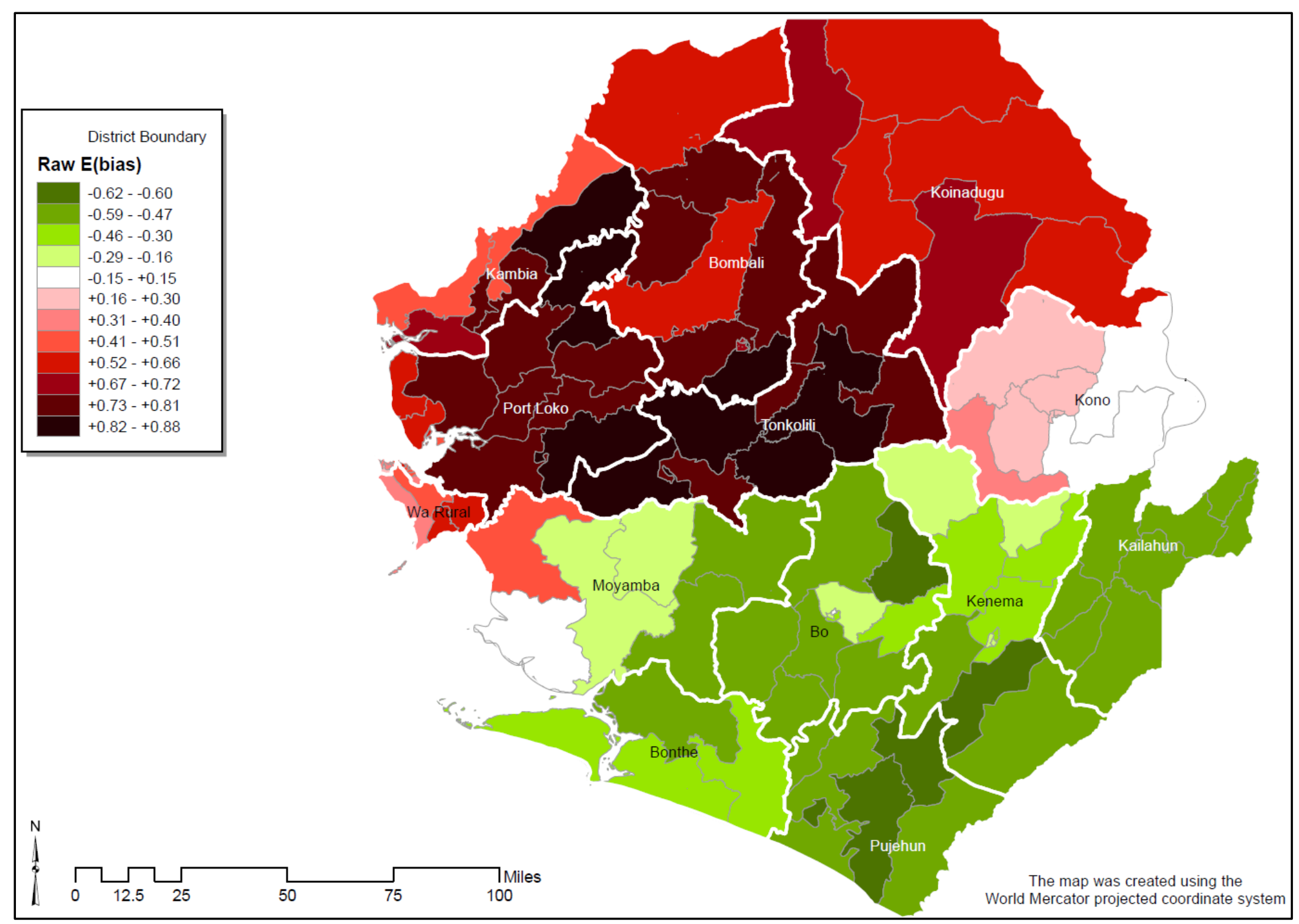


Appendix Figure 2: Map of 2008 Radio Stations and EA-level Coverage in the NPS Sample

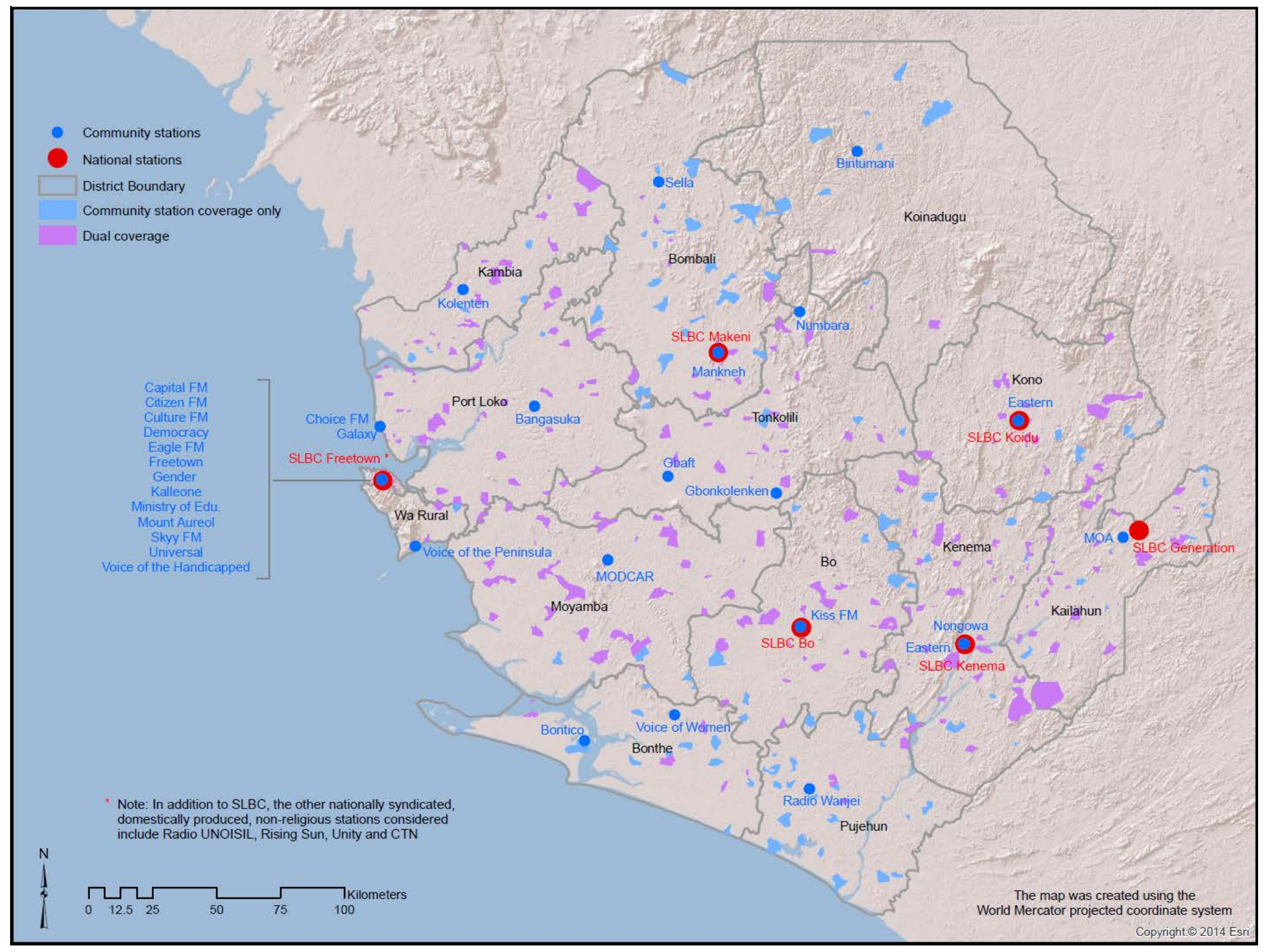


Appendix Figure 3: Correlation between Radio Coverage and Distance to Nearest Tower

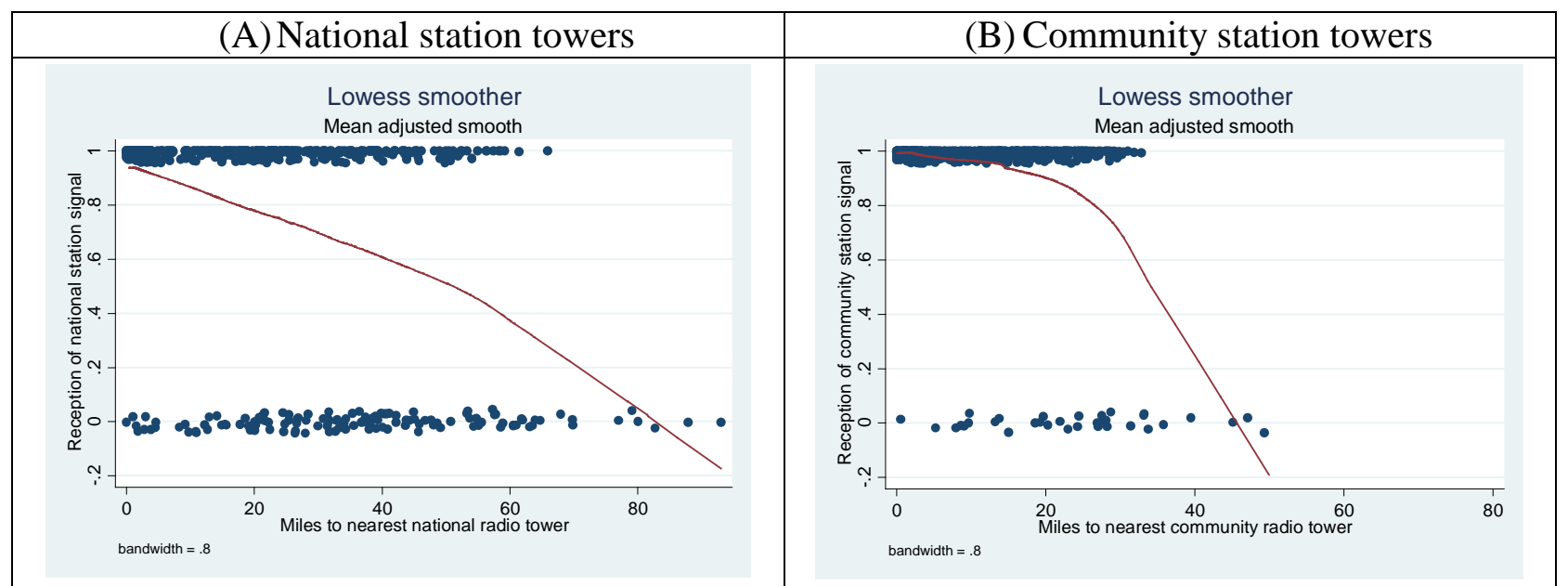

Notes: In Panel A, the downward sloping fitted line suggests that reception of nationally syndicated radio programs, as reported by village leaders in the community module of the 2008 NPS, is negatively correlated with distance to the nearest national radio transmission tower, calculated using GPS coordinates. Panel B presents a similar relationship for the reception of community-produced programs and distance to the nearest community radio station tower. 


\section{Appendix Figure 4: National Campaign Spending by Bins of Absolute Partisan Bias}

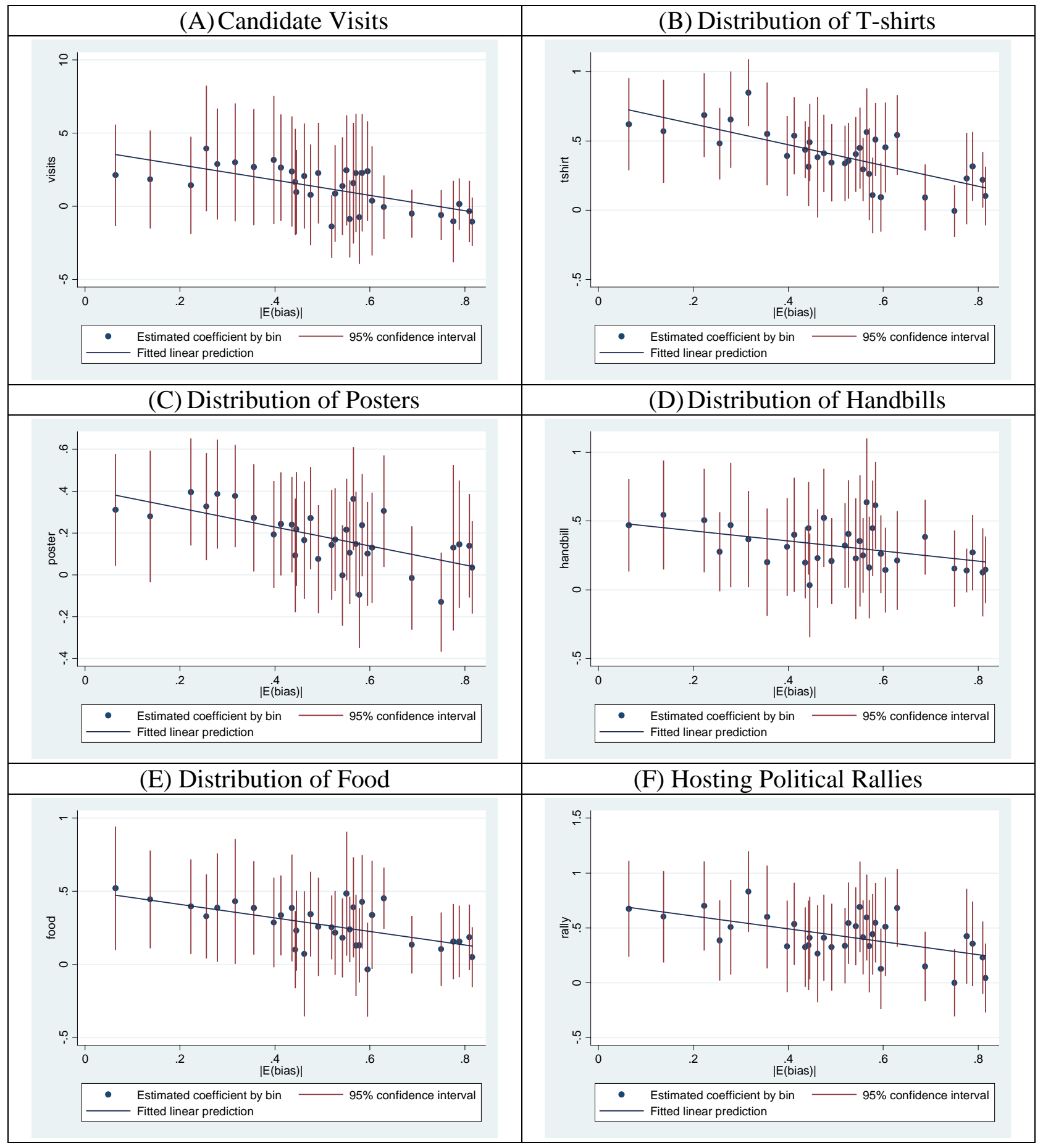

Notes: The downward sloping fitted lines suggest that campaign expenditure by national candidates is lower in more ethnically homogeneous, and hence less competitive jurisdictions, which is consistent with Proposition 1. In this analysis: i) each dot represents the estimated coefficient on absolute partisan bias from a regression of the specified campaign item distributed by national candidates on 34 equally sized bins of bias, controlling for district fixed effects, population density and population per seat, with robust standard errors clustered at the constituency level; ii) average bias in the final reference bin is 0.83 ; and iii) the underlying unit of observation is the candidate-community pair, where $\mathrm{N}$ varies by outcome, ranging from 1,765 for visits to 2,277 for posters, exactly as for the regression counterparts in Table 2, Panel A. 
Appendix Figure 5: Maps of Partisan Bias and Campaign Spending at the Constituency-level for Port Loko District

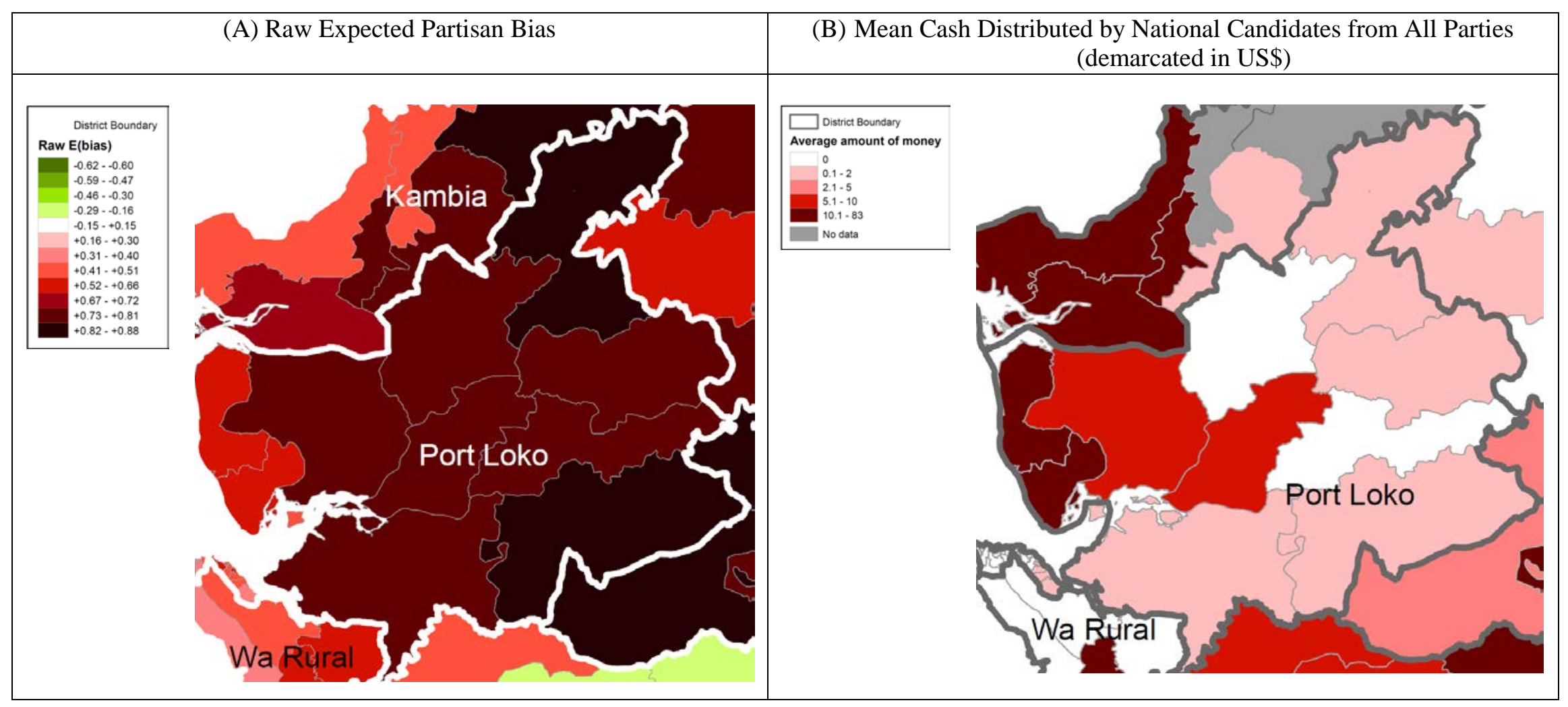

Notes: Panel A shades constituencies with respect to their expected partisan bias, calculated using ethnic population shares from the 2004 Census and the estimated strength of each ethnic group's party loyalty reported in Table 1. Panel B shades constituencies based on the average amount of cash distributed by national candidates, as reported in the community module of the 2008 NPS survey. The maps focus on one particular district, Port Loko, and show that when moving from West to East, the partisan bias favoring the APC party in Panel A increases, while campaign spending in Panel B decreases, consistent with Proposition 1. 


\section{Appendix Figure 6: Campaign Spending by Bins of Absolute Bias and Level of Election}

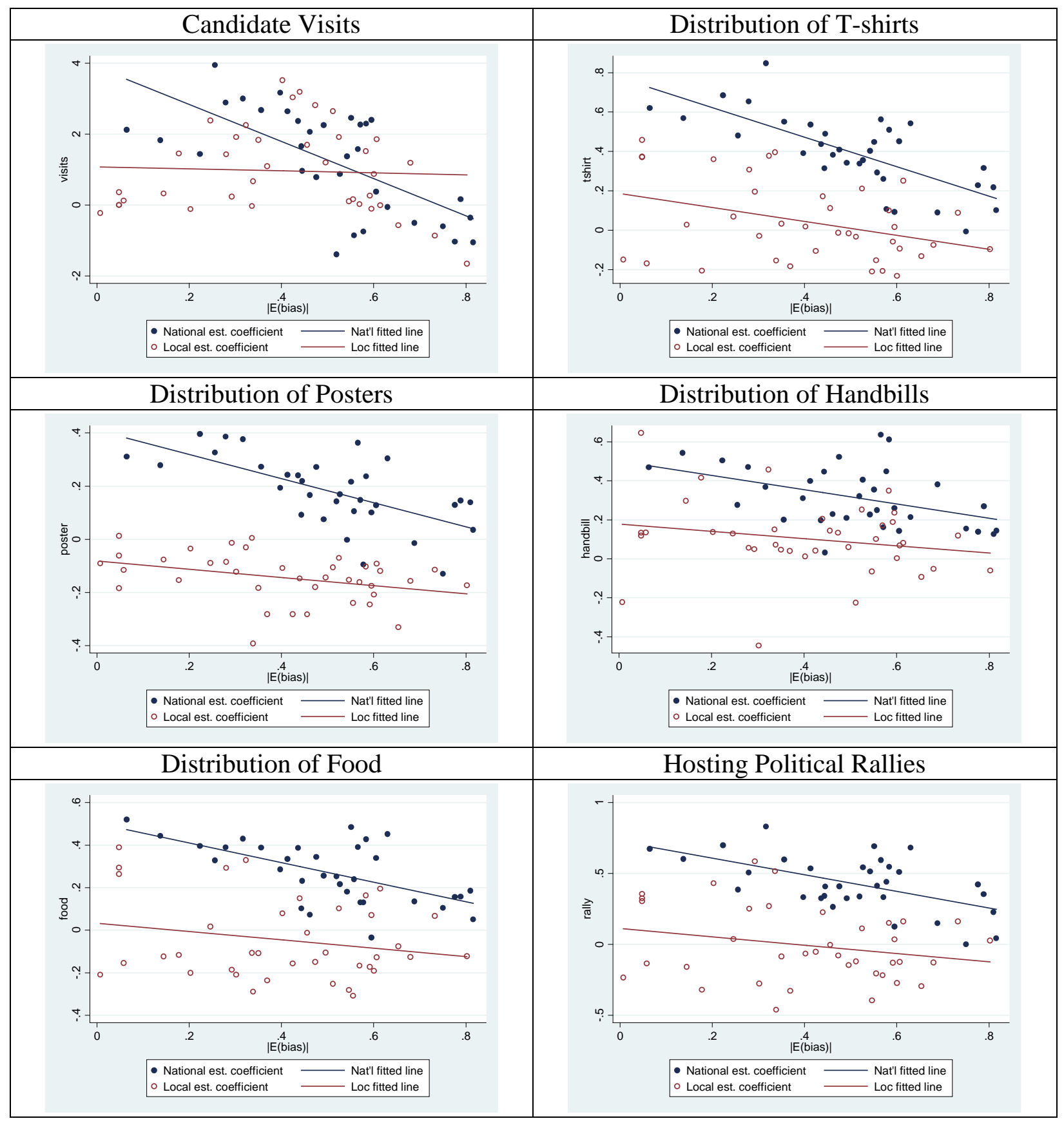

Notes: The relatively flatter fitted lines for local (compared to national) elections suggest that campaign spending responds less strongly to the ethnic composition, and hence competitiveness, of jurisdictions in local elections. Given the information advantages voters have with respect to local candidates, these differences are consistent with Proposition 3. In this analysis: i) each dot represents the estimated coefficient on absolute partisan bias from a regression of the campaign spending item on 34 (39) equally sized bins of bias, controlling for district fixed effects, population density and population per seat, with robust standard errors clustered by constituency (ward), conducted separately for national (local) candidates; ii) average bias in the final reference bin is $0.82-0.83$ at both levels; and iii) the underlying unit of observation is the candidate-community pair, $\mathrm{N}$ varies by outcome and level between 1,765 and 2,480 (see regression counterparts in main text Table 2 for exact $\mathrm{N}$ by outcome and level). 


\section{Appendix Figure 7: Differential Turnout by Level of Election and Constituency Ethnic Population Shares}

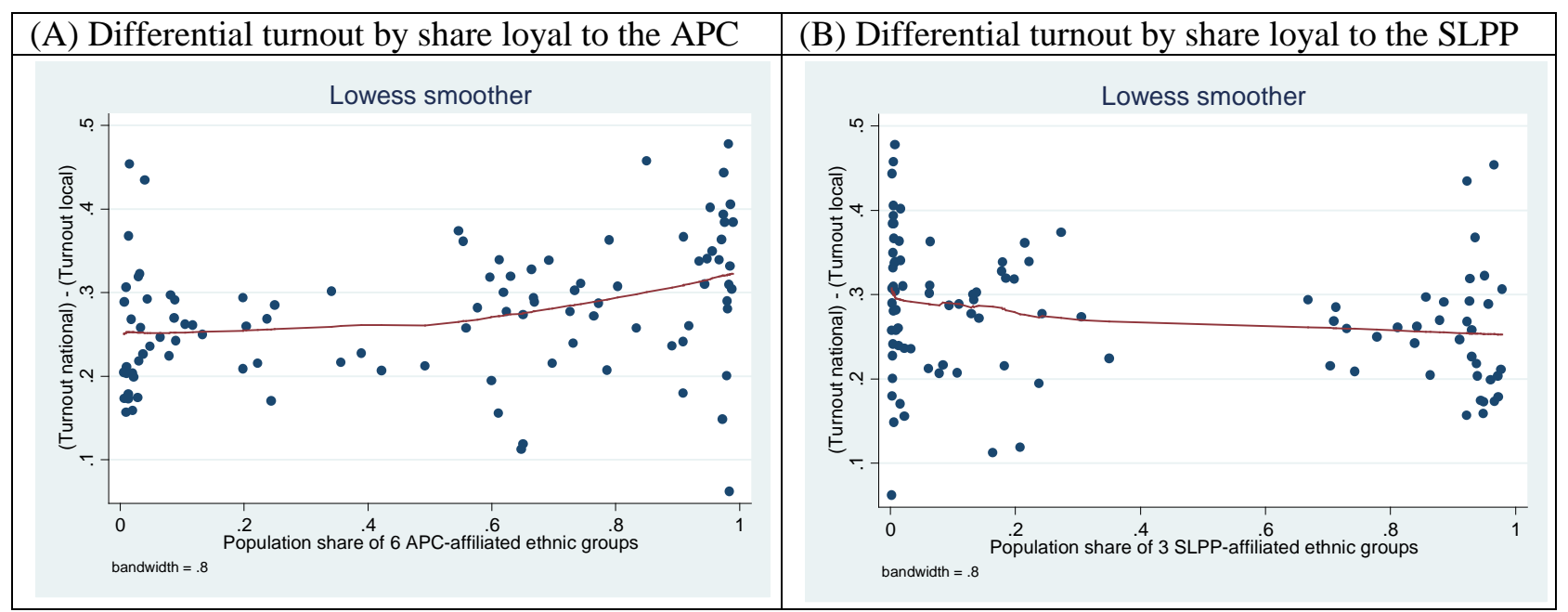

Notes: Panel A plots the difference in turnout across level of election against the population share of the six APCaffiliated ethnic groups listed in Table 1. Panel B plots differential turnout against the population share of the three SLPP-affiliated ethnic groups. Both lines are relatively flat, suggesting that differential turnout is not strongly correlated with the ethnic composition of jurisdictions, and is thus unlikely to provide an alternative explanation for Proposition 1. Data on turnout comes from the National Electoral Commission and constituency population shares by ethnicity are calculated using the 2004 Census. 
Appendix Table 1: Self-Reported Primary Determinant of Vote Choice by Level of Election

\begin{tabular}{lccc}
\hline \hline Level of election & Political party & $\begin{array}{c}\text { Candidate } \\
\text { characteristics }\end{array}$ & $\begin{array}{c}\text { Difference across factors: } \\
\text { Column (1) - (2) }\end{array}$ \\
\hline Local Council races & $(1)$ & $(2)$ & $(3)$ \\
National MP races & 34.46 & 35.47 & -1.01 \\
& 45.66 & 20.94 & $24.72^{* * *}$ \\
Difference across levels (local - national) & $-11.03^{* * *}$ & $14.54^{* * *}$ & $(2.39)$ \\
& $(3.07)$ & $(3.16)$ & \\
Number of observations & & & \\
\hline \hline
\end{tabular}

Notes: Estimates in the first row show that political party and candidate characteristics are equally likely to be the primary determinant of vote choice in local elections, while the second row shows that party is much more important than candidate attributes in determining vote choice in national races. In this analysis: i) significance levels indicated by ${ }^{*} p<0.10,{ }^{* *} p<0.05$, ${ }^{* * *} p<0.01$; ii) the unit of observation is the vote; iii) outcomes in Columns 1 and 2 reflect responses to the question "What was your first most important reason for choosing this candidate?" collected in the 2008 DSS exit polls; iv) candidate characteristics include the following responses: reputation / achievement in previous job, from same / nearby village, candidate is friend or relative, same religion, same "secret" or traditional social society, candidate's gender, candidate's education, and helped me / my family before; and v) the local - national difference estimates in row 3 are from regression analysis with individual voter fixed effects and robust standard errors clustered at the level of Local Council ward (the unit of sampling). 
Appendix Table 2: Access to Public Infrastructure Differenced over Sector and Time

\begin{tabular}{|c|c|c|c|c|}
\hline \multirow[t]{2}{*}{ Dependent variable: } & \multicolumn{4}{|c|}{ Household access to primary facility within 15 minutes walking } \\
\hline & $\begin{array}{c}\text { Education } \\
\text { (1) }\end{array}$ & $\begin{array}{c}\text { Health } \\
(2) \\
\end{array}$ & $\begin{array}{c}\text { Education } \\
(3) \\
\end{array}$ & $\begin{array}{c}\text { Health } \\
\text { (4) }\end{array}$ \\
\hline$\left|\mathrm{E}(\mathrm{bias})_{\mathrm{j}}\right|$ & $\begin{array}{l}-0.002 \\
(0.110)\end{array}$ & $\begin{array}{c}0.143 \\
(0.096)\end{array}$ & & \\
\hline Post (= 2007) & $\begin{array}{c}0.260 * * * \\
(0.039)\end{array}$ & $\begin{array}{c}0.110^{* * *} \\
(0.033)\end{array}$ & $\begin{array}{c}0.223^{* * *} \\
(0.039)\end{array}$ & $\begin{array}{c}0.090 * * * \\
(0.030)\end{array}$ \\
\hline Post $\times \mid \mathrm{E}(\text { bias })_{j} \mid$ & $\begin{array}{c}-0.263 * * * \\
(0.066)\end{array}$ & $\begin{array}{c}-0.120 * * \\
(0.053)\end{array}$ & $\begin{array}{c}-0.255^{* * *} \\
(0.066)\end{array}$ & $\begin{array}{c}-0.101^{* *} \\
(0.046)\end{array}$ \\
\hline Number of observations & 9,229 & 7,290 & 9,229 & 7,290 \\
\hline Level of fixed effects & District & District & EA village & EA village \\
\hline \multicolumn{5}{|c|}{ SUR estimation of difference in Post $\times \mid \mathrm{E}(\text { bias })_{\mathrm{j}} \mid$ for health compared to education } \\
\hline Coefficient & \multicolumn{2}{|c|}{$0.144^{*}$} & \multicolumn{2}{|c|}{$0.154^{* *}$} \\
\hline Chi squared & \multicolumn{2}{|c|}{3.33} & \multicolumn{2}{|c|}{4.24} \\
\hline $\mathrm{P}>$ chi squared & \multicolumn{2}{|c|}{0.068} & \multicolumn{2}{|c|}{0.040} \\
\hline National mean household access in 2005 & 0.437 & 0.194 & & \\
\hline National mean household access in 2007 & 0.554 & 0.242 & & \\
\hline
\end{tabular}

Notes: This table analyzes a natural policy experiment that occurred in Sierra Leone’s decentralization reform program between 2005 and 2007, where devolution of administrative and financial control over public services to local government proceeded faster for health than education. Local Councils (LCs) thus gained relatively more influence (vis$\grave{a}$-vis the central government) over primary health facilities than schools in the early reform years: e.g. while the first financial transfers to LC accounts for management of primary health were sent in 2005, devolution of primary education was delayed until June 2007 with no transfers made before then (Whiteside 2007). During the intervening two years, LCs acquired political authority and access to finances to make improvements in healthcare, and acquired neither for education. MPs retained an oversight role for both ministries throughout the period. This table thus estimates a differencein-differences test of Proposition 3, which predicts that the relative gain in influence of the LCs compared to MPs should result in a more equitable allocation of investment with respect to the political competitiveness of jurisdictions when comparing health to education over time. Analysis explores changes in household access to primary health clinics and schools collected in the February 2005 and May 2007 waves of the NPS panel survey.

Coefficients on expected partisan bias in the first row show that the inherited stock of primary health and education facilities was not systematically related to the competitiveness of constituencies. The positive and significant coefficients on the Post dummy in the second row show that household access to primary schools and primary health clinics both increased substantially from 2005 to 2007. The negative and significant coefficients on the interaction term in the third row suggest that these new investments favored lower bias (more competitive) jurisdictions in both sectors, which is consistent with Proposition 1 on swing voter incentives facing politicians at both levels of government. The positive seemingly unrelated regression (SUR) system estimates in the lower half of the table suggest that investments in health responded less strongly to the competitiveness of the jurisdiction when compared to education, consistent with the information premise of Proposition 3 dampening the swing incentives for local as compared to national government. The result is even stronger under the inclusion of enumeration area fixed effects, where the confidence level of the SUR estimate comparing Columns 3 and 4 is 96\%. These estimates, however, should be interpreted with caution given the unresolved identification challenges for this exercise: i) the plausibility of the parallel trends assumption is questionable given that the delay in devolution of education was not random, and there is no earlier pre-experiment period of democratic rule (or data) to at least establish similar pre-trends; ii) the structure and wording of the survey questions changed over time; and iii) survey responses were conditional on having a school age child in the household or usage of government health facilities.

Significance levels indicated by ${ }^{*} p<0.10,{ }^{* *} p<0.05,{ }^{* * *} p<0.01$. 
Appendix Table 3: Voter Response to Candidate Quality Using Peer Rankings of Local Incumbents

\begin{tabular}{|c|c|c|c|c|c|c|}
\hline \multirow[t]{2}{*}{ Dependent variable: } & \multicolumn{2}{|c|}{$\begin{array}{c}\text { Re-elected, } \\
\text { given incumbent }\end{array}$} & \multicolumn{2}{|c|}{$\begin{array}{l}\text { Voted for incumbent, } \\
\text { all voters }\end{array}$} & \multicolumn{2}{|c|}{$\begin{array}{l}\text { Voted for incumbent, } \\
\text { given from rival tribe }\end{array}$} \\
\hline & (1) & (2) & (3) & (4) & (5) & (6) \\
\hline Effectiveness peer rank of incumbent & $\begin{array}{c}10.82^{* * *} \\
(3.50)\end{array}$ & $\begin{array}{c}11.82 * * \\
(5.00)\end{array}$ & $\begin{array}{c}12.49 * * * \\
(3.49)\end{array}$ & $\begin{array}{c}11.23^{* * *} \\
(4.09)\end{array}$ & $\begin{array}{l}6.51^{* *} \\
(3.05)\end{array}$ & $\begin{array}{c}3.46 \\
(3.87)\end{array}$ \\
\hline Mean of dependent variable & 60.47 & 63.38 & 63.75 & 65.16 & 13.47 & 14.07 \\
\hline Unit of observation & \multicolumn{2}{|c|}{ Incumbents } & \multicolumn{2}{|c|}{ Voters } & \multicolumn{2}{|c|}{ Voters } \\
\hline Number of observations & 129 & 71 & 960 & 709 & 193 & 135 \\
\hline Number of races covered & 115 & 71 & 86 & 62 & 37 & 29 \\
\hline
\end{tabular}

Notes: This table exploits cross sectional differences in local incumbent peer rankings to provide suggestive evidence that voter choice responds to productive attributes of candidates. Following Banerjee and Pande (2009), all sitting Local Councillors ranked three standard vignettes that described the activities of hypothetical Councillors of varying degrees of effectiveness as well as three randomly selected peers (2008 DSS Wave 1). Peer rankings were translated into a seven point scale with reference to the vignettes (see details below). Each Councillor was ranked by multiple peers and I use the average across rankings. Appendix Table 4 validates this measure by showing that it negatively correlates with peer corruption rankings and positively correlates with other competence measures regarding the evaluated Councillor. Analysis considers races where one of these incumbents ran for re-election, controlling for incumbent party.

Column 1 shows that a one point increase in average peer effectiveness ranking was associated with a 10.8 percentage point (s.e. 3.5) increase in the probability of re-election. The effect is large in real world magnitude, where the predicted difference in re-election probabilities for incumbents with the worst observed peer ranking (equal to 1 ) and the best (6.4) is 58 percentage points. Column 3 uses the 2008 NPS household data to show a similar increase in support among voters, where a one point increase in peer rankings is associated with a 12.5 percentage point (s.e. 3.5) increase in the proportion of respondents who reported voting for the incumbent. Column 5 turns more directly to the phenomenon of crossing party lines by limiting the voter sample to respondents from a rival group, i.e. an ethnic group historically associated with the party challenging the incumbent. While support for the incumbent amongst rival groups is much lower than in the general population (13 versus 64 percent), the coefficient on peer effectiveness ranking is again positive and statistically significant (6.5, s.e. 3.0), indicating that these voters were more likely to cross party lines to support incumbents with higher peer rankings. Columns 2, 4 and 6 repeat these analyses on a restricted sample of wards that more closely mirrors the exit poll sample of Table 3, with similar results save the loss of significance in Column 6.

In this analysis: i) significance levels indicated by ${ }^{*} p<0.10$, ${ }^{* *} p<0.05$, ${ }^{* * *} p<0.01$; ii) Column 1 covers all wards where a Local Councillor ran for re-election (due to redistricting, in a few wards multiple incumbents ran); iii) Columns 3 and 5 include all wards covered by the NPS household sample where a single incumbent ran for re-election; iv) Columns 2, 4 and 6 exclude multi-seat LC wards, where voters can choose candidates from multiple parties, and wards where one of the two rival parties did not contest the race (i.e. those missing either an APC or SLPP/PMDC candidate); v) the sample of voters in Columns 3 through 6 is restricted to those who could verify their claim of voting by producing a voter identification card with the corresponding hole punch made by polling station staff; vi) the sample of voters in Columns 5 and 6 regarding crossing party lines is restricted to those from ethnic groups affiliated with a party in Table 1; and vii) the text of the anchoring vignettes in order of increasing effectiveness was as follows: "Councillor $X$ has attended council meetings and been a member of the development planning committee but has not been active in other ways as a councillor." "Councillor $Y$ was an active member of the development planning committee and got one of the RRI projects (a market) constructed in his ward." "Councillor $Z$ was an active member of the development planning committee and got one of the RRI projects (a market) constructed in his ward. Also, he worked with the Paramount Chief to mobilize labor and an NGO to provide funds to repair roads and culverts in the ward." Councillors rated each vignette and then three randomly assigned peers on a scale of 1 to 10 . The peer rankings were standardized to a 7 point scale ranging from 1 if the peer was ranked lower than Councillor $X, 2$ if equal to Councillor $X$ and so on up to 7 if ranked higher than Councillor $Z$. 


\section{Appendix Table 4: Correlates of the Peer Effectiveness Rank}

Dependent variables by category
Mean

(1)

0.000

2.481

0.000

0.990

0.829

0.728

0.734

0.079

0.067

0.895

0.903

0.769

0.445

0.180

0.948

0.920

0.000

1.403

0.570

0.000

3.781

1.707

0.000

0.508

0.655

0.382

0.211

Family relationship to Member of Parliament
Coefficient on rank Standard error

(2)

(3)

(0.054)

(0.052)

$(0.017)$

(0.007)

$(0.022)$

(0.014)

(0.019)

$(0.018)$

$(0.024)$

Number of observations, range

Average peer effectiveness rank of APC members (7 point scale)

3.830

Average peer effectiveness rank of SLPP members (7 point scale)

3.843

Notes: This table validates the peer effectiveness rank used in Appendix Table 3 by showing that it robustly negatively correlates with peer corruption rankings (row 1) and positively correlates with other competence measures regarding the evaluated Councillor that were captured in the DSS Wave 1 (quiz questions, committee membership and oversight visits). Sitting Councillors completed corruption rankings in the same manner as for effectiveness (although note that the scores were generally much more favorable and exhibited less variation - i.e. nearly half of all peers were ranked on par with the least corrupt vignette - and thus held little predictive power for re-election rates). The quiz questions gauge knowledge of key line ministry counterparts and local leaders, as well as familiarity with the Council budget and sources of finance. Estimates at the bottom of the table provide no evidence that the peer rankings simply reflect connections to clientelist networks as measured by familial relationships to other political leaders nor that they vary systematically by party.

In this analysis: i) significance levels indicated by $* p<0.10, * * p<0.05$, $* * * p<0.01$; ii) robust standard errors; iii) the first row of each category reports the mean effects index coefficient on rank following Kling and Liebman 2004 expressed in standard deviation units; iv) all remaining rows report the coefficient on the peer effectiveness rank from a regression of the individual outcome on the rank in units natural to the outcome; v) all specifications include demographic controls for the politician evaluated (age, gender, years of schooling, ethnicity, religion and a principal components score of assets); and vi) sample excludes rankings of Local Council Chairs / Mayors. 
Appendix Table 5: Robustness Comparison of Exit Polls to Official Voting Returns

\begin{tabular}{lc}
\hline \hline Dependent Variable: & $(1)$ \\
\hline APC party vote share in exit polls & $0.734^{* * *}$ \\
& $(0.048)$ \\
Local race & $0.115^{* *}$ \\
Local race x APC party vote share in exit polls & $(0.051)$ \\
Constant & -0.0008 \\
& $(0.083)$ \\
Number of observations & 0.035 \\
\hline \hline
\end{tabular}

Notes: This table investigates the accuracy of self-reported vote choices recorded in the DSS exit poll by comparing them to official electoral returns published by the National Electoral Commission. The large (maximum possible value equal to 1 ) and highly significant coefficient estimate in row 1 suggests that APC party vote shares aggregated from the exit polls strongly predict those in the official returns. The null result in row 3 suggests that this predictive power is no better or worse for local as compared to national vote choices. In this analysis: i) significance levels indicated by ${ }^{*} p<0.10$, ${ }^{* *} p<0.05,{ }^{* *} p<0.01$; ii) robust standard errors; and iii) the unit of observation is the jurisdiction, of which there are 57 Local Council wards and 50 Parliamentary constituencies with nonmissing vote choices in the exit poll sample. 